\title{
Ducks induce rapid and robust antibody responses than chickens at early time after intravenous infection with H9N2 avian influenza virus
}

Jianmei Yang ${ }^{1,2^{*}}$ D, Hongrui Cui ${ }^{1}$, Qiaoyang Teng ${ }^{1}$, Wenjun Ma $^{3}$, Xuesong Li ${ }^{1}$, Binbin Wang ${ }^{1}$, Dawei Yan ${ }^{1}$, Hongjun Chen', Qinfang Liu ${ }^{1}$ and Zejun Li ${ }^{1 *}$

\begin{abstract}
Background: Compared with chickens, ducks are normally resistant to avian influenza virus without clinical signs while they habor almost all subtypes of influenza A viruses. To date, however the mechanism for duck antiinfluenza has not been completely understood. The H9N2 avian influenza virus (AIV) is the most prevalent subtype of influenza A virus that infects chickens and ducks in China. However, H9N2 AIV replication and the host immune response in these domestic birds has not been systematically investigated.
\end{abstract}

Methods: In the present study, we compared the kinetics and magnitudes of antibody responses in chickens and ducks after infection with H9N2 AIV by the intranasal route or intravenous route. Furthermore, we determined the viral replication and distribution in chickens and ducks after infection with H9N2 AIV by the intravenous route.

Results: Our results revealed that the antibody response was rapid and robust in ducks than in chickens at early time (2-3dpi) after intravenous infection with H9N2 AIVs, while delayed and lower antibody detected in ducks than in chickens after intranasal infection with H9N2 AIVs. The virus was detected in multiple organs tissues in chickens but not in ducks infected by the intravenous route.

Conclusions: Our results provide the evidence that humoral immune response could play a critical role in duck resistance for influenza, which expands our knowledge on duck anti-influenza characteristics.

Keywords: Humoral immune response, Chickens, Ducks, H9N2 Alvs, Different routes

\section{Background}

Chickens and ducks are the two most predominant domestic bird species in China, and they are also the most economically important land fowl and waterfowl as sources of meat, eggs, and feathers. H9N2 AIV was first isolated from turkeys in Wisconsin (USA) in 1966 and was later first identified in chickens in Guangdong province, China in 1994 [1, 2]. Subsequently, viruses of the H9N2 subtype have quickly spread to most areas of China. Currently, H9N2 AIVs have become prevalent

\footnotetext{
*Correspondence: yangjianmei@shvri.ac.cn; lizejun@shvri.ac.cn

'Innovation Team for Pathogen Ecology Research on Animal Influenza Virus, and Department of Avian Infectious Disease, Shanghai Veterinary Research Institute, Chinese Academy of Agricultural Sciences, Shanghai 200241, People's Republic of China

Full list of author information is available at the end of the article
}

among the domestic poultry populations in several Asian countries and are considered to be potential candidates for a future pandemic $[3,4]$. Additionally, the H9N2 influenza virus has donated six internal genes to the H7N9 and H10N8 AIVs, which have recently infected humans in China $[5,6]$. Furthermore, H9N2 AIVs have been reported to infect pigs and humans, resulting in severe and even lethal cases in humans [7-10]. Although there is currently no evidence of human-to-human transmission of H9N2 AIVs, the results of serological surveillance studies found higher anti-H9 antibody positive rates in serum samples collected from poultry workers $[10,11]$. Moreover, there is evidence showing that the continual transmission of H9N2 AIVs between chickens and aquatic birds facilitates the generation of reassortant

(c) The Author(s). 2019 Open Access This article is distributed under the terms of the Creative Commons Attribution 4.0 International License (http://creativecommons.org/licenses/by/4.0/), which permits unrestricted use, distribution, and 
viruses with the potential to infect humans [12]. This emphasizes that the threat of H9N2 AIVs to public health is a growing concern $[10,13]$.

H9N2 AIVs continue to circulate in chickens despite the implementation of a long-term vaccination program [3]. Moreover, ducks have been reported to be tolerant to H9N2 AIV infection, since infected ducks typically do not exhibit any clinical symptoms; however, ducks are able to shed the virus and transmit it to other species and can be for almost all types of influenza A viruses [4]. In addition, ducks typically also serve as the natural reservoir for HPAIVs and display no clinical signs following infection, whereas chickens are more susceptible to HPAIVs [14, 15]. Studies have shown that many immune-related genes are involved in the anti-influenza responses of ducks, including innate immune, cellular immune, inflammatory and chemokine genes [16-19]. Ducks have been found to mount more active and robust cellular immune responses compared to chickens exposed to H9N2 AIV by the intranasal route [20]. Following infection with HPAIVs, ducks are able to initiate a faster but lower inflammatory cytokine response followed by the activation of major pattern recognition receptors (i.e., TLR7, RIG-I, and MDA-5) and a persistent cellular response, whereas chickens generate excessive but delayed inflammatory cytokine responses followed by inadequate cellular immune responses, which may result in a higher pathogenicity of the virus in chickens [16]. Other studies have shown that ducks can initiate an immediate and robust response to the HPAIV, A/Vietnam/1203/04 (H5N1), whereas they generate a minimal response to the LPAIV, A/mallard/BC/ 500/05(H5N2) [21]. Chemokine gene expression is also significantly higher in the lung tissues of ducks infected with HPAIV, compared to those infected with an LPAIV at 1 day post-infection (dpi) [22]. So far, the mechanism for duck anti-influenza is still in dark and has been shown complicated as different results were observed due to different virulent virus strain and viral exposure routes.

Ducks usually have no clinical signs after most LPAI infection, but some H5 HPAIVs have been found to be highly pathogenic (100\% lethal) and replicate systemically in ducks [23]. Thus, the current knowledge of AIV infection in ducks should be expanded from respiratory and intestinal infection to systemic infection [23-26]. However, the immune response generated in ducks during systemic infection remains poorly understood. Several studies have evaluated AIV tissue tropism in ducks and turkeys via the intravenous inoculation of AIVs; however, the immune response was not determined following intravenous infection [27].

Since ducks still have some unclear/unknown mechanism for anti-influenza, in the present study, we investigated the antibody responses between chickens and ducks after natural infection and systemic infection using H9N2 AIV model. In addition, the viral titer in the organs was determined in chickens and ducks after infection with H9N2 virus by intravenous route, which was used to mimic a systemic AIV infection in birds. Rapid and robust antibody responses were observed in ducks than in chickens at early time after intravenous infection.

\section{Methods}

\section{Virus and animals}

A/chicken/Shanghai/441/2009 (H9N2), designated SH441, was amplified in nine-day-old specific pathogen-free (SPF) chicken embryos (Beijing Merial Vital Laboratory Animal Technology Co., Ltd., Beijing, China). SH441 was titrated in SPF chicken embryos before it was used for infection or immunization. Allantoic fluids containing the $\mathrm{SH} 441$ virus were inactivated with $0.05 \% \beta$-propiolactone (BPL; Sigma-Aldrich, St. Louis, MO, USA) at $4{ }^{\circ} \mathrm{C}$ for $12 \mathrm{~h}$ to be used as an inactivated vaccine and was confirmed by infecting in nine-day-old SPF chicken embryos for 3 days to check the HA titer.

Chickens and shelducks aged 10-12 weeks old were hatched from SPF embryos (chicken embryos were obtained from Beijing Merial Vital Laboratory Animal Technology Co., Beijing; duck embryos were obtained from Harbin Veterinary Research, Harbin) and housed in isolators until further analysis.

\section{Infection of chickens and ducks by intranasal or intravenous route}

For each route, two groups were set up, each containing five chickens or five ducks. The same dose was administered to each bird: 1) for the intranasal infection route (mimic viral natural infection), each bird in both groups was intranasally infected with the live SH441 virus at a dose of $10^{6} 50 \%$ embryo infectious dose $\left.\left(\mathrm{EID}_{50}\right) / 100 \mu \mathrm{L} ; 2\right)$ for the intravenous infection route (viral systemic infection), each bird was intravenously inoculated with the live SH441 virus at a dose of $10^{6} \mathrm{EID}_{50} / 100 \mu \mathrm{L}$.

To determine the virus replication in the organs of infected chickens and ducks through the intravenous route, nine chickens and nine ducks were intravenously inoculated with the live SH441 virus at a dose of $10^{6}$ $\mathrm{EID}_{50} / 100 \mu \mathrm{L}$. Three birds were necropsied at 1,2 , and 3 dpi, and 13 different tissues (tonsil, spleen, trachea, lung, intestine, brain, thymus, heart, liver, kidney, fabricius, pancreas, and ovary/testis) were collected for further analysis. 
Antibody responses in chickens and ducks exposed to the H9N2 virus

Blood was collected at different time points for each experiment. The serum samples were then used to test the antibody response using both a hemagglutination inhibition (HI) assay, which is the gold standard influenza antibody test, and a blocking ELISA (enzyme linked immunosorbent assay), which we developed previously [28].

The HI assay was performed according to recommendations of the OIE manual. Briefly, the sera were serially diluted (two-fold) in V-bottom 96-well plates and mixed with a standard amount of virus (8 HA units). Then, $0.5 \%$ chicken erythrocytes were added to each well and the plates were incubated for $30 \mathrm{~min}$ at room temperature. The HI endpoint was the highest serum dilution in which no agglutination was observed.

The blocking ELISA method has been shown to have a high correlation value of $96.9 \%$ with the $\mathrm{HI}$ assay and had a greater sensitivity for low antibody responses, with concrete numerical values compared to the $\mathrm{HI}$ assay [28] Briefly, non-immune sera from SPF chickens and ducks were used as the negative reference sera. Positive reference sera for the H9N2 virus were prepared and stored in our laboratory. The reduction in the $\mathrm{OD}_{450}$ value caused by serum antibodies blocking $\mathrm{mAb}$ binding was calculated for each sample using the following formula: PI (Percentage of Inhibition, $\%)=\left(\mathrm{OD}_{450}\right.$ value of negative reference serum - $\mathrm{OD}_{450}$ value of tested serum $) /\left(\mathrm{OD}_{450}\right.$ value of negative reference serum $\mathrm{OD}_{450}$ value of positive reference serum) $\times 100 \%$.

\section{Virus titer in the organs of birds following the intravenous infection route}

To evaluate viral replication and tissue tropism in chickens and ducks following the intravenous infection, 13 different organ tissues were collected from three chickens and three ducks at 1,2 , and 3 days post-infection (dpi), respectively. Each tissue was weighed and homogenized in PBS containing $100 \mathrm{U} / \mathrm{mL}$ penicillin and $100 \mu \mathrm{g} / \mathrm{mL}$ streptomycin at a $1: 1(\mathrm{~mL} / \mathrm{g})$ ratio to tissue homogenates, which were centrifuged at $5000 \times g$ for 10 $\min$ at $4{ }^{\circ} \mathrm{C}$. The supernatants were collected for viral titration in SPF eggs.

We next intra-allantoically injected 9-11-day-old chicken embryonated eggs with $100 \mu \mathrm{L}$ of the supernatants of tissue homogenates. The viral titer for each organ was determined by the Reed and Muench method and expressed as $\log _{10} \mathrm{EID}_{50} / \mathrm{g}$ of tissue [29].

\section{Statistical analysis}

Antibody responses based on $\mathrm{HI}$ and blocking ELISA were analyzed by analysis of variance (ANOVA) in GraphPad Prism version 5.0 (GraphPad software Inc., CA,USA). A value of $p \leq 0.05$ was considered to be significant. Pair-wise mean comparisons between chicken and duck groups were made using Student's $T$ test.

\section{Results}

Antibody response in birds intranasally infected with the H9N2 virus

Following intranasal infection with the H9N2 virus, three out of five chickens seroconverted at $4 \mathrm{dpi}$ to a positive $\mathrm{HI}$ titer $\left(\mathrm{HI}>\log _{2} 4\right)$ and all chickens $(5 / 5)$ seroconverted at 6 dpi with a higher HI titer and inhibition according to the results of the blocking ELISA (PI > 25\%) (Fig. 1). In contrast, none of the infected ducks seroconverted at $4 \mathrm{dpi}$ and $5 \mathrm{dpi}$, until four out of five ducks (4/5) were sera positive at $6 \mathrm{dpi}$ and all ducks (5/ 5) seroconverted at $7 \mathrm{dpi}$. Noticeably, a significantly higher antibody titer was detected in the chickens than in the ducks from 7 dpi to the experimental end point $(18 \mathrm{dpi})(p<0.01)$ (Fig. 1). These results reveal that ducks display delayed seroconversion (at least 2 days delayed) compared to chickens when they are intranasally infected with the H9N2 virus.

\section{Antibody response in birds intravenously infected with the H9N2 virus}

Following intravenous infection with the H9N2 virus, the antibody response in both ducks and chickens was higher compared to that generated following intranasal infection (Figs. 1 and 2). All of the chickens (5/5) and ducks (5/5) seroconverted at $2 \mathrm{dpi}$. Noticeably, the antibody titers in the ducks were higher than those in the chickens at the early time points $(2 \mathrm{dpi}, 2.5 \mathrm{dpi}$, and 3 dpi). All serum samples were also assessed via a blocking ELISA. Similar to the HI results, the ducks were associated with a significantly higher antibody response than chickens at the early time points $(2-3 \mathrm{dpi})$ following intravenous infection $(p<0.01)$ (Fig. 2a and b). In contrast, the antibody titers in the chickens increased to the same level or moderately higher levels than those exhibited by the ducks from $3.5 \mathrm{dpi}$ to the experimental end point (6 dpi) (Fig. 2a and b). To confirm this finding, another independent experiment was performed by intravenously infecting both types of birds with the H9N2 virus. The antibody titers in the ducks were significantly higher than those in the chickens at $3 \mathrm{dpi}(p<0.01)$, and the antibody titers in chickens increased a little higher than ducks from 4-6dpi (Fig. 2c and d).

\section{Virus replication in the organs of birds intravenously infected with the H9N2 virus}

To our knowledge, this is the first study to show that ducks can produce a significantly higher specific antibody response than chickens following $\mathrm{H} 9 \mathrm{~N} 2$ virus infection, which was observed by the intravenous infection 

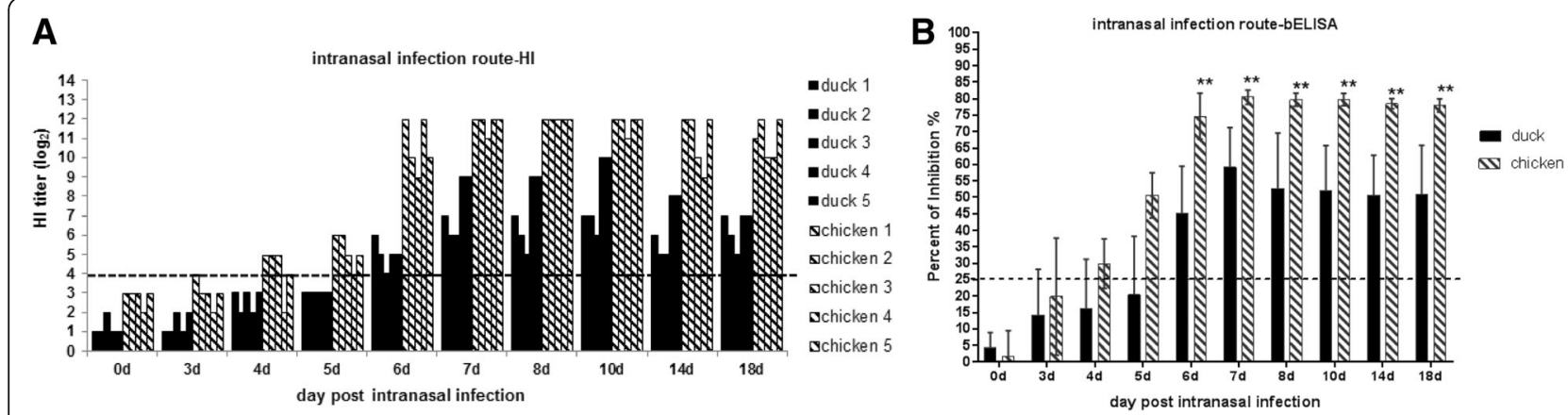

Fig. 1 Antibody response in chickens and ducks intranasally infected with the H9N2 virus. a A hemagglutination inhibition (HI) assay was performed to test the serum samples of birds at the indicated time points ( $\mathrm{HI}>\log _{2} 4$ was considered positive). $\mathbf{b} \mathrm{A}$ blocking ELISA was used to test the serum samples of birds at the indicated time points (PI $>25 \%$ was considered positive; ${ }^{* *}, p<0.01$ )

route (Fig. 2). To further understand how the virus replicates in the infected birds following intravenous infection with $\mathrm{H} 9 \mathrm{~N} 2$, viral titers were determined by titration in SPF eggs using different tissues collected from infected birds at 1,2 , and 3 dpi.

After intravenous infection with the H9N2 virus, the chickens exhibited a systemic infection characterized by higher viral replication titers and a wider tissue tropism compared to the ducks. At $1 \mathrm{dpi}$, the virus was detected in the tonsil, spleen, thymus, fabricius, and trachea of all $(3 / 3)$, as well as in one intestine, kidney, and testis $(1 / 3)$ sample collected from the chickens (Fig. 3a - c \&
Table 1). At $2 \mathrm{dpi}$, the virus was also detected in the brain (1/3), heart (2/3), and pancreas (1/3) samples from the chickens, and viral titers were substantially increased at $3 \mathrm{dpi}$ in all of these tissue samples (Fig. 3b-c \& Table 1). In contrast, at $1 \mathrm{dpi}$, the virus was detected in only three duck lungs (3/3), with no virus detected in any of the other duck organs. At $2 \mathrm{dpi}$, the virus was only detected in one out of three duck lungs (1/3) and tonsil (1/3) samples. At $3 \mathrm{dpi}$, the virus was detected in one out of three duck tonsil (1/3) and trachea (1/3) samples, and no virus replication was detected in the duck lungs at $3 \mathrm{dpi}$ $(0 / 3)$ (Fig. 3a-c \& Table 1). The viral titers were

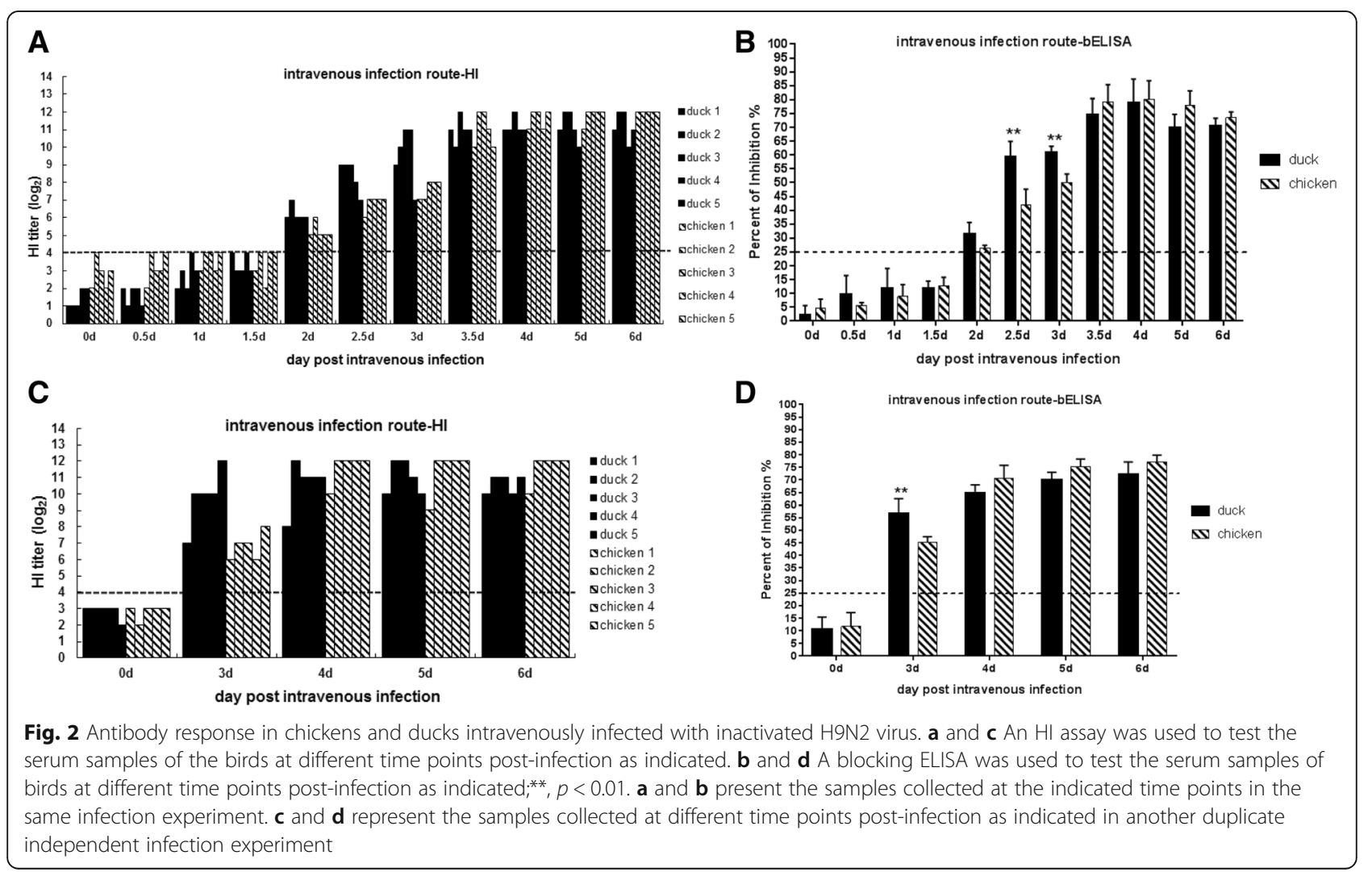



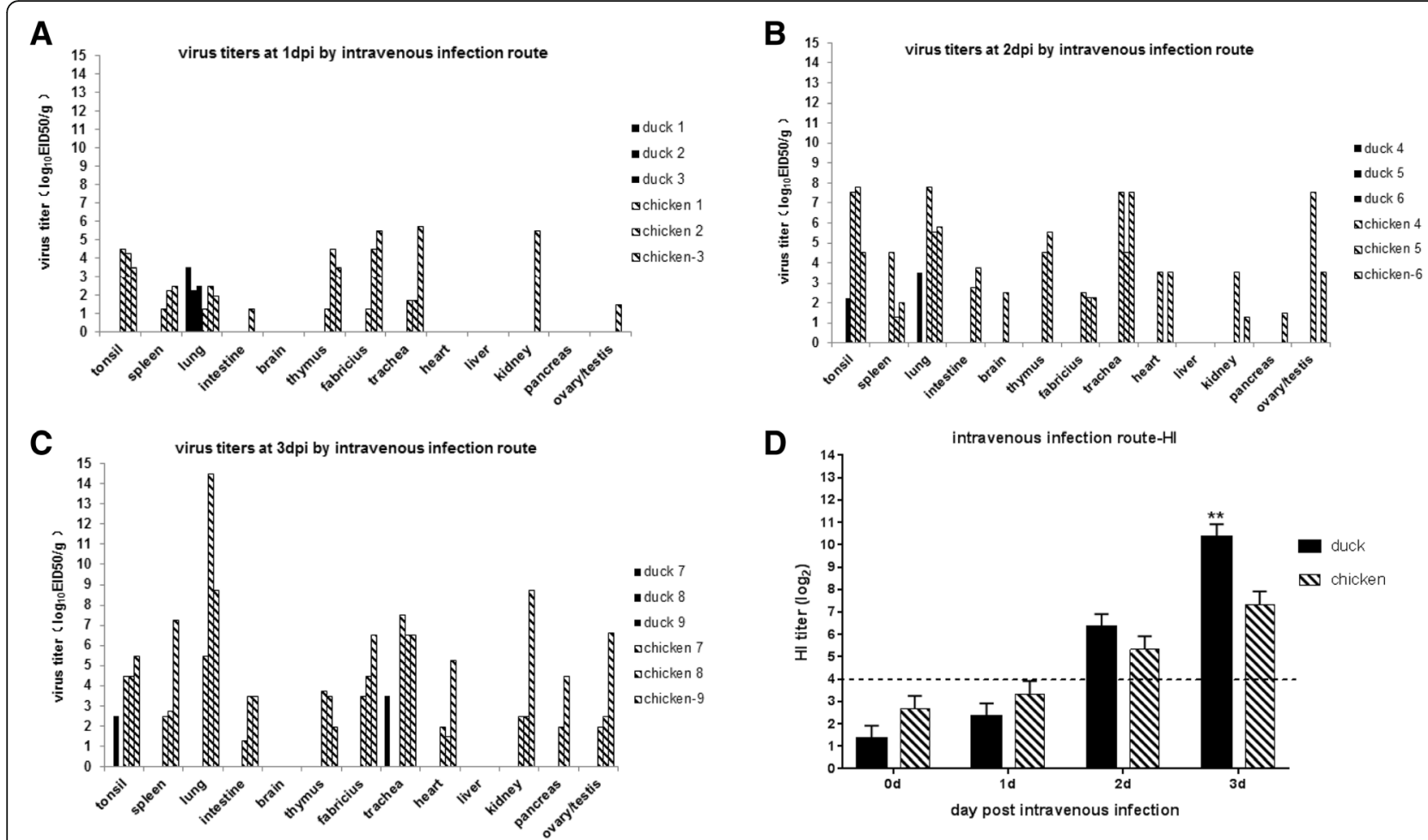

Fig. 3 Virus titer and $\mathrm{HI}$ antibody responses of chickens and ducks intravenously infected with the H9N2 virus. a - c Virus titers were determined in 13 different organs of birds at the indicated time points: $1 \mathrm{dpi}(\mathbf{a}), 2 \mathrm{dpi}(\mathbf{b})$, and $3 \mathrm{dpi}(\mathbf{c})$. $\mathbf{d} \mathrm{An} \mathrm{HI}$ assay was used to test the serum samples of the birds at the indicated time points. dpi: days post-infection

substantially higher in all chicken organs compared with the duck organs, except for the duck lungs at 1 dpi. Viral titers were higher in the chicken lungs and tracheas at 2 dpi and 3 dpi with $4.5-14.5 \log _{10}$ EID $_{50} / g$ tissue (Fig. 3b-c).

In addition, the antibody responses were also determined by an $\mathrm{HI}$ assay. The ducks produced higher antibody titers than the chickens at $2 \mathrm{dpi}$ and $3 \mathrm{dpi}$, especially at $3 \mathrm{dpi}(p<0.01)$, which was consistent with the findings as we previously described in this study (Figs. 2 and $3 \mathrm{~d}$ ).

\section{Discussion}

In contrast to chickens, ducks are normally resistant to most influenza A virus infections and do not exhibit clinical symptoms; however, the mechanisms associated with duck anti-influenza remain poorly understood. Based on the current available knowledge, both local mucosal and innate immunity are considered to play a critical role in duck anti-influenza responses $[17,21,30]$. Although the innate immune response is highly effective for antiviral infection, it is not specific or sufficient for providing a defense against viral infection, that is why ducks can be for almost all subtypes of influenza A viruses. The acquired immune response activated by MHC molecules is critical for eliminating viral infections through the generation of virus-specific antibodies.
However, the specific antibody responses of chickens and ducks infected with AIVs have not been fully characterized. Thus, we aimed to investigate such responses in this study.

Some researchers showed that ducks had a deficit in adaptive antibody to AIV because of genetics-linked characteristics, which may contribute to weak antibody responses and the perpetuation of the virus in this animal reservoir [31]. In this present study, ducks really showed the weaker antibody responses including delayed seroconversion and lower HI antibody titers than chickens by intranasal infection route (viral natural infection), which is consistent with previous findings. However, by intravenous infection route (viral systemic infection), ducks inversely could produce robust antibody responses than chickens with antibody levels at early time after infection $(2,2.5,3 \mathrm{dpi})$. In previous studies, ducks could also show strong and sensitive antibody responses when exposed to attenuated viruses [32-34]. The specific antibody response could be detected as early as at 3-6 dpi in ducks by intranasal or intramuscular immunization with DTMU (duck Tembusu) attenuated viruses [32]. A marked increased level of DEV-specific IgG antibodies in duck serum were detected as early as at $6 \mathrm{dpi}$ by orally infection with virulent DEV (duck enteritis virus) Chv strain [34] or 
Table 1 Virus titers determined by titration in SPF eggs for different tissues from chickens and ducks intravenously infection with H9N2 virus

\begin{tabular}{|c|c|c|c|c|c|c|c|c|c|c|c|c|c|c|}
\hline \multirow[t]{2}{*}{ Time } & \multirow[t]{2}{*}{ Animal } & \multicolumn{13}{|c|}{ Virus titers in different tissues $\left(\log _{10} \mathrm{EID}_{50} / \mathrm{g}\right)$} \\
\hline & & tonsil & spleen & lung & intestine & brain & thymus & fabricius & trachea & heart & liver & kidney & pancreas & $\begin{array}{l}\text { Ovary } \\
\left.\text { (testis }^{b}\right)\end{array}$ \\
\hline \multirow[t]{6}{*}{$1 \mathrm{dpi}$} & Duck 1 & $p^{a}$ & I & 3.5 & / & I & I & / & I & I & I & / & I & 1 \\
\hline & Duck 2 & / & / & 2.25 & / & / & / & / & / & / & / & / & / & / \\
\hline & Duck 3 & / & / & 2.5 & / & I & / & / & / & / & / & / & / & / \\
\hline & Chicken 1 & 4.5 & 1.25 & 1.25 & / & I & 1.25 & 1.25 & 1.75 & I & / & / & / & $\rho^{\mathrm{b}}$ \\
\hline & Chicken 2 & 4.25 & 2.25 & 2.5 & 1.25 & / & 4.5 & 4.5 & 1.75 & / & / & 5.5 & & $1.5^{\mathrm{b}}$ \\
\hline & Chicken 3 & 3.5 & 2.5 & 1.98 & / & / & 3.5 & 5.5 & 5.75 & / & / & / & / & / \\
\hline \multirow[t]{6}{*}{$2 \mathrm{dpi}$} & Duck 4 & / & / & & / & / & / & / & / & / & / & / & / & / \\
\hline & Duck 5 & / & / & 3.5 & / & / & / & / & / & / & / & / & / & I \\
\hline & Duck 6 & 2.25 & / & / & / & / & / & / & / & / & I & / & / & I \\
\hline & Chicken 4 & 7.5 & 4.5 & 7.75 & / & 2.5 & 4.5 & 2.5 & 7.5 & 3.5 & & 3.5 & & 7.5 \\
\hline & Chicken 5 & 7.75 & 1.25 & 5.5 & 2.75 & / & 5.5 & 2.25 & 4.5 & / & / & / & / & I \\
\hline & Chicken 6 & 4.5 & 1.98 & 5.75 & 3.75 & & & 2.25 & 7.5 & 3.5 & & 1.25 & 1.5 & 3.5 \\
\hline \multirow[t]{6}{*}{$3 \mathrm{dpi}$} & Duck 7 & / & / & / & / & / & / & / & 3.5 & & / & / & / & I \\
\hline & Duck 8 & 2.5 & / & / & / & / & / & / & / & / & / & / & / & I \\
\hline & Duck 9 & / & / & / & / & / & / & / & / & / & / & / & / & / \\
\hline & Chicken 7 & 4.5 & 2.5 & 5.5 & 1.25 & I & 3.75 & 3.5 & 7.5 & 1.98 & / & 2.5 & 1.98 & $1.98^{\mathrm{b}}$ \\
\hline & Chicken 8 & 4.5 & 2.75 & 14.5 & 3.5 & / & 3.5 & 4.5 & 6.5 & 1.5 & / & 2.5 & 4.5 & $2.5^{\mathrm{b}}$ \\
\hline & Chicken 9 & 5.5 & 7.25 & 8.75 & 3.5 & / & 1.98 & 6.5 & 6.5 & 5.25 & / & 8.75 & / & $6.64^{\mathrm{b}}$ \\
\hline
\end{tabular}

a Note: /, means no virus was detected from this sample in SPF eggs; and other numbers in this table are described as log ${ }_{10}$ EID ${ }_{50} / g$ for their virus titers

b , means this sample was from duck or chicken testis

byvaccinated with DEV Cha strain [33]. These results indicated that ducks actually could have strong ability in their antibody response when exposed to virus infection or vaccination by some routes, which were also evidenced by our findings of ducks could produce higher antibody response than chickens at early time than chickens by intravenous infection of H9N2 AIVs (Figs. 2 and 3).

In this study, ducks displayed delayed seroconversion with a lower HI antibody titer compared with chickens infected with the same dose of virus via the intranasal route (viral natural infection). In order to mimic the systemic infection in chickens and ducks, we infected chickens and ducks through the intravenous route. The results showed that live H9N2 viruses induced a faster and higher antibody response compared to the intranasal route (Figs.1 and 2). Interestingly, the ducks exhibited an unexpectedly higher antibody titer compared to chickens at the earlier time points $(2-3 \mathrm{dpi})$ when they were infected intravenously. However, a similar antibody response was observed in both species at the later time points, which was confirmed by independent and different assays (Figs. 2 and 3).

Furthermore, following intravenous infection, chickens but not ducks displayed a systemic infection, as the virus was detected in 12 out of 13 organs collected in the infected chickens with a higher titer compared to the limited detection in ducks. The lung and trachea were the most severely affected organs in the chickens, followed by the fabricus (bursa), tonsil, and spleen (Fig. $3)$. The viral tropism was narrow in some duck respiratory and immune organs, as viral replication could only be detected in the lungs ( $3 / 3$ at $1 \mathrm{dpi}$ and $1 / 3$ at $2 \mathrm{dpi}$ ), trachea, (1/3 at $3 \mathrm{dpi})$, and tonsil $(1 / 3$ at $3 \mathrm{dpi})$ of the ducks. In addition, the viral titers in the ducks were quite low and the virus was quickly cleared from the duck lungs at 3 dpi (0/3 at 3 dpi) (Fig. 3). A previous study isolates of pheasant and turkey origin isolates were more pathogenic in turkeys, but had limited distributions and effects in ducks after intravenous inoculation [27]. Moreover, the pancreas was the most severely affected organ in turkeys, followed by the kidney and liver, whereas the spleen and bursa were the most commonly affected organs in ducks [27], which also suggested that immune organs of ducks were the targets of influenza A virus after intravenous infection as shown in this study (Fig. 3).

Based on our knowledge, this is the first study to reveal that intravenous infection with the LPAIV H9N2 virus can induce a rapid and robust humoral immune response in ducks at early time points (2-3dpi), but not in chickens, in which a systemic infection is observed, 
similar to HPAIV infection. In contrast no systemic infection was observed in ducks.

The ducks are resistant to most influenza A virus infection, which is related with innate immunity, and most likely also associates with the specific antibody responses as shown in this present study. The robust antibody response at 2-3dpi detected in ducks could be helpful for limiting virus spread in vivo, so the virus replicated poorly in ducks compared with in chickens. However the mechanism of the rapid and robust antibody responses in ducks infected through the intravenous route than in chickens at early time remains unclear and needs to be investigated in the future studies.

\section{Conclusion}

Our results showed that, compared to chickens, following intranasal infection with an H9N2 AIV, the antibody immune response was delayed in ducks, whereas a rapid and robust humoral immune response was induced at early time points in ducks. when intravenously infected with the H9N2 AIV. Furthermore, the virus was detected in multiple organs in chickens but not in ducks infected through the intravenous route. These findings provide the evidence that the humoral immune response could play an important role in duck resistance for influenza, and expand our current knowledge on duck anti-influenza characteristics.

\section{Abbreviations}

AIV: Avian influenza virus; DEV: Duck enteritis virus; dpi: Day post-infection; DPV: Duck plague virus; DTMUV: Duck tembusu virus; EID $50.50 \%$ embryo infectious dose; ELISA: Enzyme linked immunosorbent assay; HI: Hemagglutination inhibition; HPAIV: Highly pathogenic avian influenza virus; LPAIV: Low pathogenic avian influenza virus; OIE: Office International Des Epizooties; PI: Percentage of inhibition; SPF: Specific pathogen-free

\section{Funding}

This study was supported by the National Natural Science Foundation of China $(31700136,31472206)$, Shanghai Key Laboratory of Veterinary Biotechnology Open Project (klab201706), the Chinese Academy of Agricultural Sciences Central-level Nonprofit research Institutes Fundamental Research Funds for the project (2017JB16 and 2018JB02), and the National Key Research and Development Program of China (2016YFD0500106). This study is collaborative research by the Shanghai Veterinary Research Institute, CAAS-Kansas State University Research Laboratory Collaboration for Animal influenza and Poultry Disease.

\section{Availability of data and materials}

The datasets used and analyzed during the current study are included within this article and in additional file.

\section{Authors' contributions}

$J Y$ and ZL conceived and designed the experiments. JY, HC, QT, XL, BW, DY, $\mathrm{QL}$ and $\mathrm{HC}$ conducted experimental work. JY, WM and ZL analyzed the data and wrote the paper. All authors read and approved the final manuscript.

\section{Ethics approval}

The animal studies in this research were conducted in accordance with guidelines of animal welfare of World Organization for Animal Health. The protocols for animal and embryonated chicken egg experiments were approved by the the Animal Care and Use Committee of SHVRI,CAAS (approval number: SHVRI-RO-0008; 2014)
Consent for publication

Not applicable.

\section{Competing interests}

The authors declare that they have no competing interests.

\section{Publisher's Note}

Springer Nature remains neutral with regard to jurisdictional claims in published maps and institutional affiliations.

\section{Author details}

${ }^{1}$ Innovation Team for Pathogen Ecology Research on Animal Influenza Virus, and Department of Avian Infectious Disease, Shanghai Veterinary Research Institute, Chinese Academy of Agricultural Sciences, Shanghai 200241, People's Republic of China. ${ }^{2}$ Shanghai Key Laboratory of Veterinary Biotechnology, Shanghai 200240, People's Republic of China. ${ }^{3}$ Department of Diagnostic Medicine/Pathobiology, College of Veterinary Medicine, Kansas, State University, Manhattan, Kansas 66506, USA.

Received: 20 December 2018 Accepted: 20 March 2019 Published online: 11 April 2019

References

1. Homme PJ, Easterday BC. Avian influenza virus infections. I. Characteristics of influenza A-Turkey-Wisconsin-1966 virus. Avian Dis. 1970;14:66-74.

2. Chen B, Zhang Z, Chen W. Isolation and identification of avian influenza virus. Chin J Vet Med. 1994;20:3-5.

3. Sun Y, Liu J. H9N2 influenza virus in China: a cause of concern. Protein Cell. 2015:6:18-25.

4. Guo YJ, Krauss S, Senne DA, Mo IP, Lo KS, Xiong XP, Norwood M, Shortridge KF, Webster RG, Guan Y. Characterization of the pathogenicity of members of the newly established H9N2 influenza virus lineages in Asia. Virology. 2000;267:279-88.

5. Ma C, Lam TT, Chai Y, Wang J, Fan X, Hong W, Zhang Y, Li L, Liu Y, Smith DK, et al. Emergence and evolution of H10 subtype influenza viruses in poultry in China. J Virol. 2015;89:3534-41.

6. Gao R, Cao B, Hu Y, Feng Z, Wang D, Hu W, Chen J, Jie Z, Qiu H, Xu K, et al. Human infection with a novel avian-origin influenza a (H7N9) virus. N Engl J Med. 2013;368:1888-97.

7. Huang Y, Li X, Zhang H, Chen B, Jiang Y, Yang L, Zhu W, Hu S, Zhou S, Tang $Y$, et al. Human infection with an avian influenza a (H9N2) virus in the middle region of China. J Med Virol. 2015;87:1641-8.

8. Butt KM, Smith GJ, Chen H, Zhang L, Leung YH, Xu KM, Lim W, Webster RG, Yuen KY, Peiris JS, Guan Y. Human infection with an avian H9N2 influenza a virus in Hong Kong in 2003. J Clin Microbiol. 2005:43:5760-7.

9. Xu C, Fan W, Wei R, Zhao H. Isolation and identification of swine influenza recombinant a/swine/Shandong/1/2003(H9N2) virus. Microbes Infect. 2004;6:919-25.

10. Peiris M, Yuen KY, Leung CW, Chan KH, Ip PL, Lai RW, Orr WK, Shortridge KF. Human infection with influenza H9N2. Lancet. 1999;354:916-7.

11. Wang Q, Ju L, Liu P, Zhou J, Lv X, Li L, Shen H, Su H, Jiang L, Jiang Q. Serological and virological surveillance of avian influenza a virus H9N2 subtype in humans and poultry in Shanghai, China, between 2008 and 2010. Zoonoses Public Health. 2015:62:131-40

12. Li KS, Xu KM, Peiris JS, Poon LL, Yu KZ, Yuen KY, Shortridge KF, Webster RG, Guan Y. Characterization of H9 subtype influenza viruses from the ducks of southern China: a candidate for the next influenza pandemic in humans? J Virol. 2003:77:6988-94.

13. Khan SU, Anderson BD, Heil GL, Liang S, Gray GC. A systematic review and meta-analysis of the Seroprevalence of influenza a(H9N2) infection among humans. J Infect Dis. 2015;212:562-9.

14. Chen H, Deng G, Li Z, Tian G, Li Y, Jiao P, Zhang L, Liu Z, Webster RG, Yu K. The evolution of H5N1 influenza viruses in ducks in southern China. Proc Natl Acad Sci U S A. 2004;101:10452-7.

15. Zeng X, Tian G, Shi J, Deng G, Li C, Chen H. Vaccination of poultry successfully eliminated human infection with H7N9 virus in China. Sci China Life Sci. 2018:61(12):1465-73.

16. Cornelissen JB, Vervelde L, Post J, Rebel JM. Differences in highly pathogenic avian influenza viral pathogenesis and associated early inflammatory response in chickens and ducks. Avian Pathol. 2013;42:347-64. 
17. Huang Y, Li Y, Burt DW, Chen H, Zhang Y, Qian W, Kim H, Gan S, Zhao Y, Li $J$, et al. The duck genome and transcriptome provide insight into an avian influenza virus reservoir species. Nat Genet. 2013;45:776-83.

18. Wei L, Jiao P, Song Y, Cao L, Yuan R, Gong L, Cui J, Zhang S, Qi W, Yang S, Liao M. Host immune responses of ducks infected with H5N1 highly pathogenic avian influenza viruses of different pathogenicities. Vet Microbiol. 2013;166:386-93

19. Cornelissen JB, Post J, Peeters B, Vervelde L, Rebel JM. Differential innate responses of chickens and ducks to low-pathogenic avian influenza. Avian Pathol. 2012:41:519-29.

20. Huang Z, Fang D, Lv P, Bian X, Ruan X, Yan Y, Zhou J. Differential cellular immune responses between chickens and ducks to H9N2 avian influenza virus infection. Vet Immunol Immunopathol. 2012;150:169-80.

21. Vanderven HA, Petkau K, Ryan-Jean KE, Aldridge JR Jr, Webster RG, Magor KE. Avian influenza rapidly induces antiviral genes in duck lung and intestine. Mol Immunol. 2012:51:316-24.

22. Fleming-Canepa X, Brusnyk C, Aldridge JR, Ross KL, Moon D, Wang D, Xia J, Barber MR, Webster RG, Magor KE. Expression of duck CCL19 and CCL21 and CCR7 receptor in lymphoid and influenza-infected tissues. Mol Immunol. 2011:48:1950-7.

23. Sturm-Ramirez KM, Ellis T, Bousfield B, Bissett L, Dyrting K, Rehg JE, Poon L, Guan Y, Peiris M, Webster RG. Reemerging H5N1 influenza viruses in Hong Kong in 2002 are highly pathogenic to ducks. J Virol. 2004;78:4892-901.

24. Hinshaw VS, Bean WJ, Webster RG, Sriram G. Genetic reassortment of influenza a viruses in the intestinal tract of ducks. Virology. 1980;102:412-9.

25. Webster RG, Yakhno M, Hinshaw VS, Bean WJ, Murti KG. Intestinal influenza: replication and characterization of influenza viruses in ducks. Virology. 1978; 84:268-78.

26. Shi J, Deng G, Ma S, Zeng X, Yin X, Li M, Zhang B, Cui P, Chen Y, Yang H, Wan X, Liu L, Chen P, Jiang Y, Guan Y, Liu J, Gu W, Han S, Song Y, Liang L, Qu Z, Hou Y, Wang X, Bao H, Tian G, Li Y, Jiang L, Li C, Chen H. Rapid Evolution of H7N9 Highly Pathogenic Viruses that Emerged in China in 2017. Cell Host Microbe. 2018:24(4):558-68.e7

27. Laudert E, Halvorson D, Sivanandan V, Shaw D. Comparative evaluation of tissue trophism characteristics in turkeys and mallard ducks after intravenous inoculation of type a influenza viruses. Avian Dis. 1993;37:773-80.

28. Yang J, Dai X, Chen H, Teng Q, Li X, Rong G, Yan L, Liu Q, Li Z. Development of blocking ELISA for detection of antibodies against H9N2 avian influenza viruses. J Virol Methods. 2015:229:40-7.

29. Reed $L$, Muench $\mathrm{H}$. A simple method of estimating fifty percent endpoints. Am J Epidemiol. 1938;27:493-7.

30. Kang $\mathrm{H}$, Wang $\mathrm{H}, \mathrm{Yu} \mathrm{Q}$, Yang $\mathrm{Q}$. Effect of intranasal immunization with inactivated avian influenza virus on local and systemic immune responses in ducks. Poult Sci. 2012:91:1074-80

31. Magor KE. Immunoglobulin genetics and antibody responses to influenza in ducks. Dev Comp Immunol. 2011;35:1008-16.

32. Li G, Gao X, Xiao Y, Liu S, Peng S, Li X, Shi Y, Zhang Y, Yu L, Wu X, et al. Development of a live attenuated vaccine candidate against duck Tembusu viral disease. Virology. 2014;450-451:233-42.

33. Qi X, Cheng A, Wang M, Yang X, Jia R, X. C. Induction of IgA,lgM and lgG antibodies in ducklings immunized with qttunuated Duck Plague Virus vaccine strain. Sci Agric Sin 2008, 41:3305-3310.

34. Qi X, Yang X, Cheng A, Wang M, Zhu D, Jia R, Luo Q, Chen X. Intestinal mucosal immune response against virulent duck enteritis virus infection in ducklings. Res Vet Sci. 2009;87:218-25.

Ready to submit your research? Choose BMC and benefit from:

- fast, convenient online submission

- thorough peer review by experienced researchers in your field

- rapid publication on acceptance

- support for research data, including large and complex data types

- gold Open Access which fosters wider collaboration and increased citations

- maximum visibility for your research: over $100 \mathrm{M}$ website views per year

At BMC, research is always in progress.

Learn more biomedcentral.com/submissions 